\title{
CAN Bus Module and Wiper Motor Compatibility Issues Research And Analysis
}

\author{
Shao-Feng LI ${ }^{a,{ }^{*}}$, Shan-Hu YU, Xiao-An LIU, Xiao-Ming WANG \\ No. 188, Central Road, dian_kou Town, Zhuji, Zhejiang, China \\ a070151902@163.com \\ *Corresponding author
}

Keywords: CAN-Bus-module, Filtering, PWM, Show of Hands, Recharge-voltage.

\begin{abstract}
The CAN bus module used in passenger cars has the potential problems of short service life, maloperation and control inaccuracy, etc. In order to improve the reliability and operational stability of the module, the following issues are investigated: (1) Using PWM output to improve the service life of the module power chip; (2) Using filter processing technology or showing of hands to reduce the noise which disturb of the module to distinguish the cam signal; (3) Using diode to suppress the recharge voltage to disturb of the module. After the practical application with different types of wiper motor, it shows that the above method can well solve the compatibility of the module and the wiper motor, greatly improving the reliability and stability of the CAN bus module.
\end{abstract}

\section{Introduction}

With the wide application of CAN bus module in automobile field, the connection difficulty and complexity of automobile are greatly reduced, and the versatility of automotive electrical circuit design is enhanced. However, the CAN bus module has many problems, such as short service life, inaccurate wiper control and poor anti-interference ability when controlling the wiper motor. These problems have been bothering us.

Because of the defects in the module to directly control the wiper motor, the current bus control of rain wiper motor, there are various methods commonly used : (1) The relay and the bus module come together to control; (2) the pure relay control, including two common relay and a wiper intermittent relay; (3) the wiper control module to control. No matter what kind of way to increase the complexity and cost of the line, Using relays to control, but also introduce new difficulties electromagnetic interference, Because the relay in the suction moment, the electromagnetic radiation is very large, Affect other electronic equipment on the vehicle, especially the radio work normally [1][2].

At present, all kinds of methods can't control wiper motor very well. Therefore, how to control wiper motor efficiently and precisely has become a top priority. In this paper, a large number of field test data, a detailed analysis of the reasons for the above results, in view of the above problems, the modified CAN bus module, the module can control the wiper motor direct accurate, efficient, and practical application prove that by different manufacturers, different types of wiper motor, can the compatibility issue is the CAN bus module and wiper motor, and reduces the production cost, has a certain reference value.

\section{Analysis and Solution of Excessive Transient Current of Wiper Motor}

Wiper motors are divided into vacuum, pneumatic and electric motors according to power. Electric wiper motor consists of winding and permanent magnet. Permanent magnet motors are widely used because of their outstanding advantages, such as small size, light weight, simple structure, reliable operation, high efficiency, flexible and diverse motor shapes and sizes. This paper mainly studies the compatibility between CAN bus module and DC permanent magnet wiper motor. The interface between the CAN bus module and the DC permanent magnet wiper motor is shown in Fig.1. 


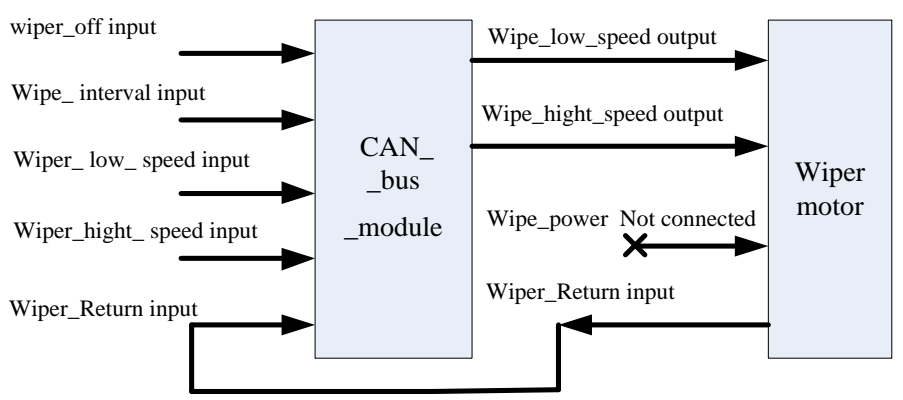

Fig. 1 Sketch map of wiper motor and bus module

Wipe_low_speed output: (1)After the low speed input of the wiper is effective, the module controls the wiper to operate at low speed. After the wiper of the low-speed input is invalid, the module collects the wiper return signal and controls the wiper to stop at low speed after the signal is valid. (2)After the interval input of the wiper is effective, Wiper low speed output a cycle, and then stop the output for a certain time (usually set to $5 \mathrm{~S}$ ), and then start the next low speed output cycle, and cycle again and again.

Wipe_hight_speed output : After the high speed input of the wiper, the module controls the wiper to operate at high speed. After the wiper input is invalid, the module controls the wiper to operate at low speed. After the module collects the wiper return signal, it controls the wiper to stop at low speed.

Wipe_power : not connected.

\section{Analysis of Excessive Starting Current of Wiper Motor}

The starting of a DC motor is a complicated process, and its starting time can be approximately described by the following formula:

$$
\begin{aligned}
& \mathrm{U}=\mathrm{Ea}+\mathrm{IaR}+2 \Delta \mathrm{Us} \\
& \mathrm{Ea}=(\mathrm{PZaN} \Phi) /(60 \mathrm{~K}) \\
& (1)+(2): \mathrm{U}=(\mathrm{PZaN} \Phi) /(60 \mathrm{k})+\mathrm{IaR}+2 \Delta \mathrm{Us}
\end{aligned}
$$

$\mathrm{U}$ is the terminal voltage, and the $\mathrm{R}$ is the armature winding resistance; $2 \Delta \mathrm{U}_{\mathrm{s}}$ is the contact voltage drop on a positive and negative pair of brushes, usually constant; Ea is the induction electromotive force of armature winding; $\mathrm{P}$ is the polar logarithm of the motor; $\mathrm{Za}$ is the total conductor number of the armature winding; $\mathrm{K}$ is the branch logarithm, and $\mathrm{N}$ is the motor speed; $\Phi$ Total magnetic flux (Generally constant). According to (3), When the wiper motor starts, the motor speed is $n=0$, Therefore, the power supply voltage all falls on the armature winding resistance, As the motor's internal resistance is very small, leading to the impact of the current is very large, generally reached the motor rated current of 10-20 times, If do not take certain measures, excessive starting inrush current will damage the module power chip [1] [2](Power chip: BTS 7810K).

\section{Method for Solving Excessive Starting Current of Motor}

According to the study in document, the power chip can be protected by ramp voltage, We use the adjustable PWM duty cycle output voltage ramp. PWM Average voltage (U Average)=(U. t) / T (Fig. 2). 


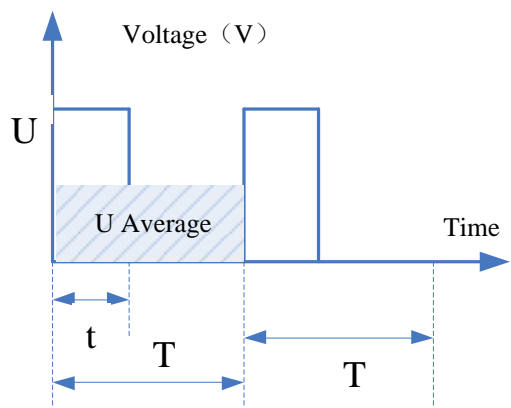

Fig.2 Calculation of average voltage of PWM

According to the literature, set $\delta=500 \mathrm{~ms}$, set $\mathrm{T}$ is $50 \mathrm{~ms}$, get 10 stage PWM(Fig.3)and Ramp function(Fig.4). The shadow in Fig.3 is the average voltage of PWM, $t$ is $10 \mathrm{~ms}$, Just design the $10 \mathrm{~ms}$ interrupt program in the program, You can get the PWM output. In this way, it can effectively suppress the impact of the excessive starting current on the power chip.

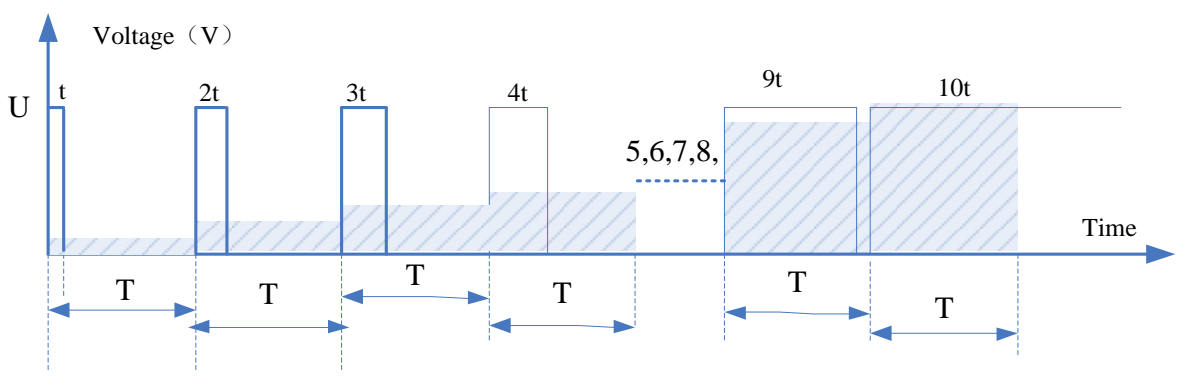

Fig.3 10 stage PWM output

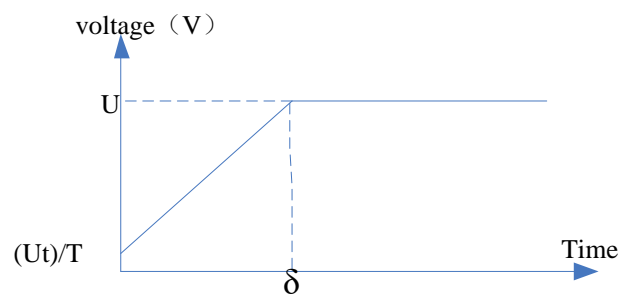

Fig.4 ramp voltage

\section{Interference Analysis and Solution of Wiper Motor Return Signal}

\section{Interference Analysis of Return Signal of Wiper Motor}

The wiper return signal is used to control the start and stop of the wiper motor, if the return signal is too noisy (see Fig.5 A), it will Influence module recognition. As a result, either the rain stopped or the rain stopped accidentally. No matter what kind of result it was, it caused inconvenience to the driver and was likely to cause traffic accidents. Fig.6 is the mechanism of the wiper return signal, At first, B and C are interlinked (Fig.6); At this moment; the B is suspended, so the $\mathrm{C}$ is also suspended, and the voltage of the $\mathrm{C}$ comes from the voltage of the module, In Fig.5 B, it's about 3.7V. With the wiper rotation along the A direction, when the wiper to the Fig. 6 B position, The B is disconnected from the $\mathrm{C}$, and the $\mathrm{C}$ is connected to the $\mathrm{D}$ (ground wire), when the wiper return signal voltage is about $0 \mathrm{~V}$ (Fig.5 B). The voltage is collected by the module, the wiper is controlled to stop running. 


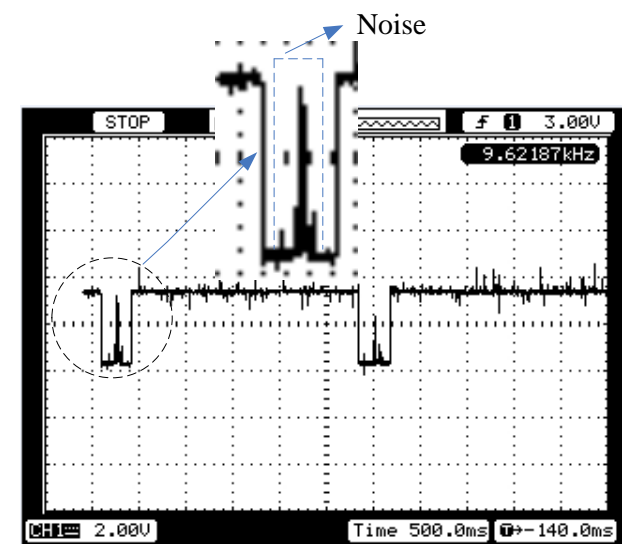

A Return_signal with noise interference

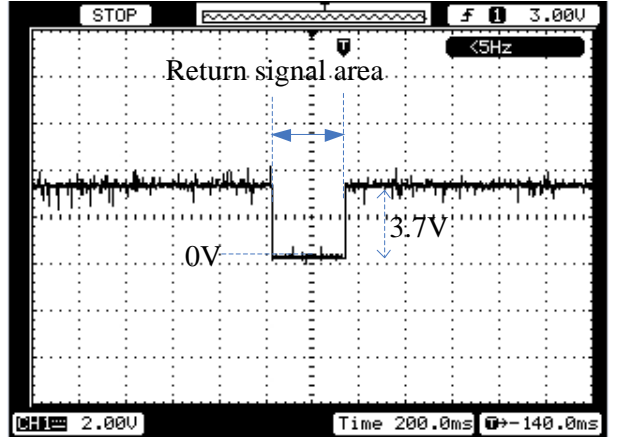

B Return_signal without noise interference

Fig.5 contrast signal of wiper return_signal

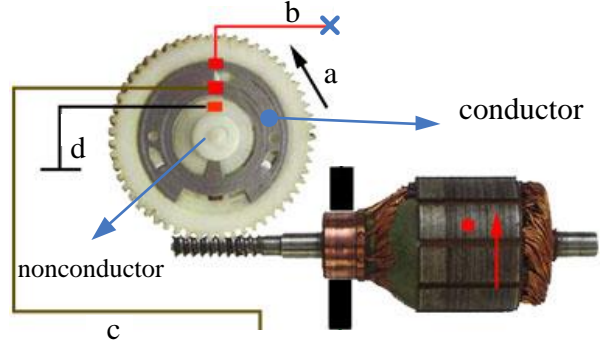

A

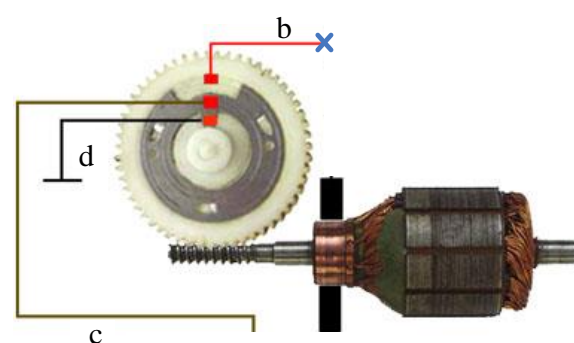

B

a: The direction of the wiper's rotation b: Wiper_power_pin(see Fig.1), It is suspended in practical application. c: Return_signal(see Fig.1).d: Wiper_ground_wire.

Fig.6 Mechanism of internal return signal of wiper

Actual test found that the signal wiper return signal is not shown in Fig.5 B, but as shown in Fig.5 A , This interference may be caused by the ground wire [3] [4] in the car or by the manufacturer of the wiper manufacturer. The interference of the ground wire on the vehicle is generally due to the unequal ground to ground. Distributed connections should be used so that there is voltage difference between ground and ground[5].

\section{Interference Solution of Wiper Motor Return Signal}

The module acquisition signal is only using rising edge triggered sampling, low level triggered sampling, or triggered sampling along the falling edge, For the return signal shown in Fig.7, there are two rising edges $(b \rightarrow c$ and $d \rightarrow e)$, Two falling edges $(a \rightarrow b$ and $c \rightarrow d)$, Two low level $(b$ and d),Either way, it will be disturbed. 


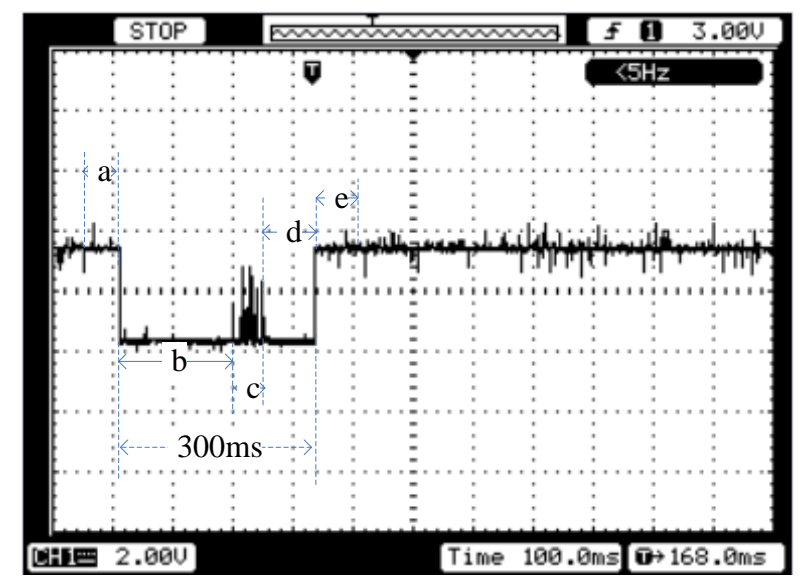

Fig.7 Interference return signal diagram under oscilloscope test

Because of the randomness and sudden noise, The module has a high demand for noise immunity, The following ways can improve the anti-interference ability of the module: (1) add a filter in the program to filter the noise: With the delay, once the acquisition to the return signal after a period of time (Fig.7), the return signal is $300 \mathrm{~ms}$, so the delay time is $500 \mathrm{~ms}$ or $1 \mathrm{~s}$, the maximum delay time not more than a wiper cycle time.) And then collect the return signal. The advantage of this method is that the program is relatively simple and has no requirement for the main cycle of the program. The disadvantage is that the interference to the non - return area is invalid (as shown in Fig.8).

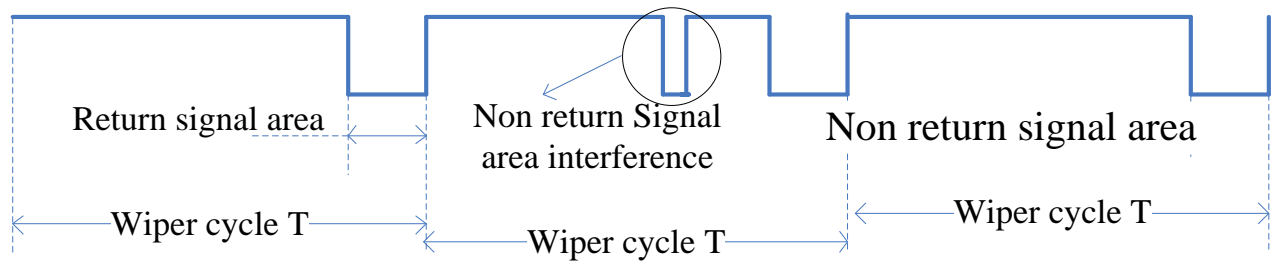

Fig.8 non return signal area interference

(2)Show of hands. This approach requires multiple sampling, followed by the majority to the minority principle, For example, 10 of these samples have 7 times the acquisition of the return signal is valid, then that the return signal is indeed valid. The advantages of this approach, not afraid of interference of non return zone; disadvantage is that the program is relatively complex, and the cycle time and the main program is short, can guarantee to be able to collect the required number in $300 \mathrm{~ms}$.

\section{The Analysis and Solutions for Recharge Voltage of Wiper Motor at Low Speed}

Wiper on the DC permanent magnet motor is implemented by changing the brush series connection between conductors for speed. It's made by three carbon brushes: negative brush, high speed brush and low speed brush. When the motor is running, negative brush by electric current, the position of the high-speed and low-speed brush varies according to the design of the motor. When DC motor is working, in order to produce counter electromotive force at the same time around the armature, the direction opposite to the direction of the armature current, if you want to make the armature rotation, applied voltage must overcome the effect of back emf, namely $U>$ counter electromotive force. When the armature speed $\mathrm{n}$ rises, counter electromotive force also rise accordingly, only when the applied voltage $\mathrm{U}$ is almost equal to the counter electromotive force (ignoring internal voltage_pressure drop of the armature winding), the speed of the armature to stabilise.

\section{Analysis of Low_Speed Recharge Voltage of Wiper Motor}

When the motor rotates, The reverse electromotive force armature winding is generated as shown in 
Fig.9, When the switch $\mathrm{K}$ is switched to low gear (Fig.9), the supply voltage $\mathrm{U}$ is added between the low speed positive brush and the negative brush, There are two parallel branches between low and negative charged brush brush, a branch is linked by 1,2,3,4 coil; the other is a branch linked by coil 5,6,7,8; When all the back EMF produced by the two coils is balanced with the supply voltage, the motor is stabilized and rotated at a low speed and a low gear. When the switch is switched to "H", the supply voltage is between the positive and negative brushes (Fig.10), As can be seen in the diagram, one of the armature windings is connected in series by 5 coil 1,2,3,4,8, and the other is in series with 3 coil 5,6,7. Wherein, the coil 8 is opposite to the back electromotive force of the coil $1,2,3,4$ and counteracts each other, Turn into only 3 coils of back electromotive force, the number of series conductors smaller, in order to balance with the power supply voltage, so only increase the speed to achieve a new balance.

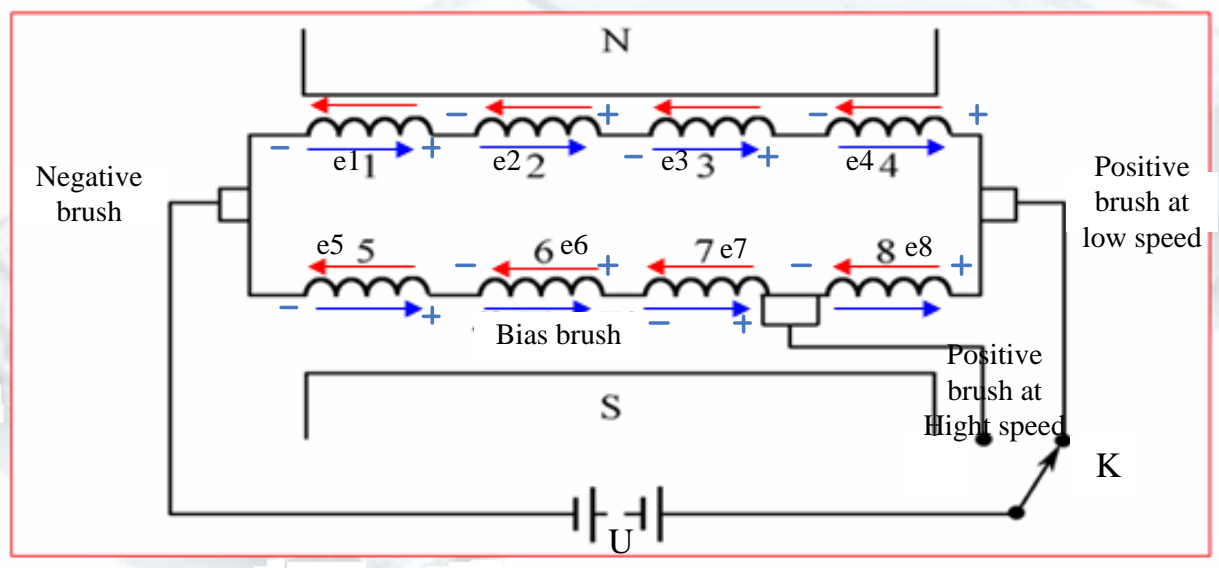

Fig.9 Wiper low speed

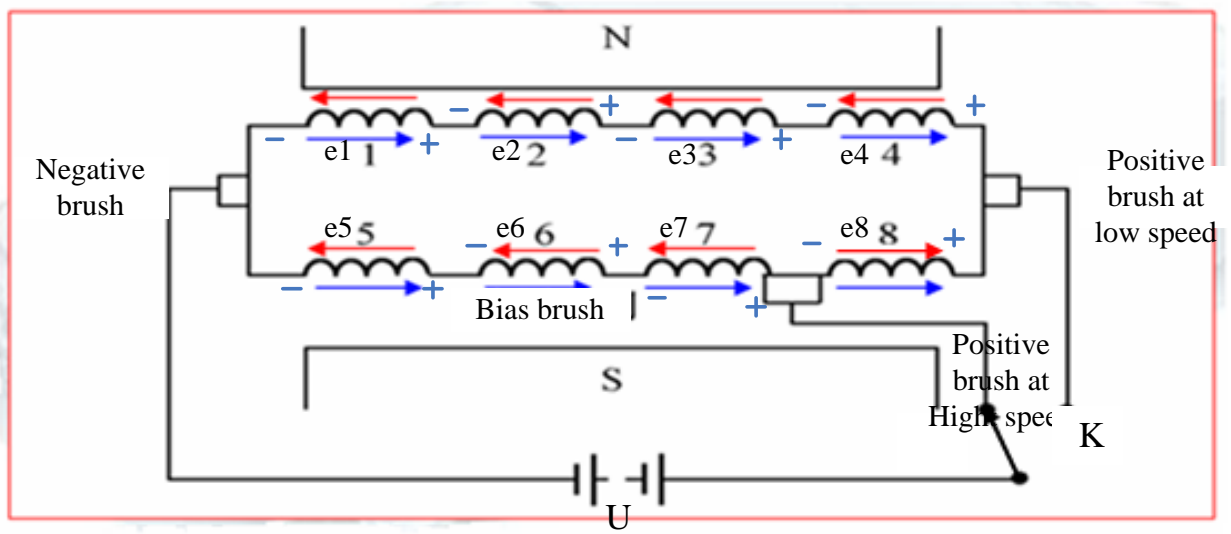

Fig.10 Wiper high speed

\section{The Solutions for Recharge Voltage of Wiper Motor at Low Speed}

According to the anlysis above, you can figure out equations below when the wiper runs at a high speed:

$$
\begin{aligned}
& \mathrm{U}=\mathrm{e} 1+\mathrm{e} 2+\mathrm{e} 3+\mathrm{e} 4-\mathrm{e} 8 \\
& \mathrm{Uc}=\mathrm{e} 1+\mathrm{e} 2+\mathrm{e} 3 \\
& \text { Based on(4)and(5): } \\
& \mathrm{Uc}=\mathrm{U}+\mathrm{e} 8
\end{aligned}
$$

According to (6), the voltage of $U c$ is higher than the supply voltage $U$, namely when the wiper motor running in high gear, the low end of windscreen wiper exists a voltage (Fig.1 a wiper speed output pin), and the voltage $53 \mathrm{~V}$ is higher than the supply (24 to $28 \mathrm{v}$ ) voltage of the wiper (Fig. 10 $\mathrm{U}$ is power supply). Due to the output of the power chip (7810 k) BTS contains a diode (shown in Fig. 11 b), the recharge voltage come along the dotted line in Fig. $11 \mathrm{c}$ into the internal chip. 


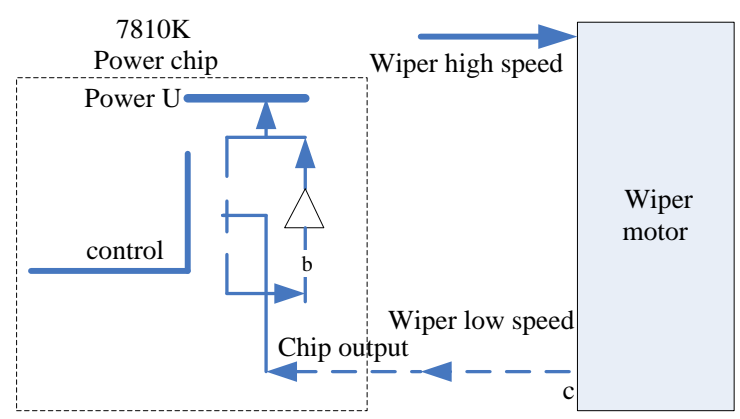

Fig.11 Voltage recharge

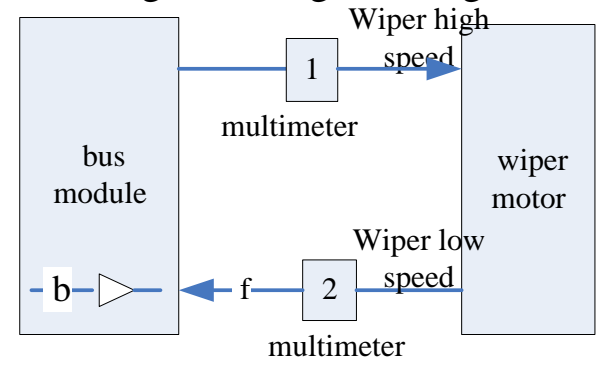

Fig.12 Current test

Because the power chip BTS 7810k is a multi-input multi-output chip, when the wiper run at the top gear and low gear powered by 7810k, test no-load wiper motor according to the way of Fig.12, found that the current is about 5.7A on multimeter 1 , the current is about $3 \mathrm{~A}$ on multimeter 2 , when cut off the line $\mathrm{f}$, the current is about $2.7 \mathrm{~A}$ on multimeter 1 . It says that the refilling energy also comes from the output of the power chip, it means that when the wiper run at high speed or low speed powered by the same chip, it lead to power chip passed 6A more current. When the wiper works on top gear, because the full load current is much larger than no-load current, so the power chip sustain overspray current in actual operation, lead to overheating chip, at the same time, because the chip has overheating protection function, affecting the normal output of the chip, lead to irregular operation of wiper motor. The solution:

(1) Use divided power chips when the wiper works at speed and low speed. Do this has the advantage of no additional costs. The disadvantage is that, to a certain extent solve the overheating of the chip due to recharge, the performance and improvement of the product make little sense.

(2) Add a high power diode at the wiper low speed module output to suppress the recharge voltage (as shown in Fig.12 b). The advantage is thoroughly solve the problem of recharge, greatly improve the performance of the product. Defect is increased cost, limit the wiper speed output pin.

\section{Conclusion}

This article in view of the existing products of deficiencies in the wiper motor control, a detailed analysis of the causes of, and gives the detailed solution, improved the bus module, improve the stability and reliability of the products.

A lot of loading operations show that it has a strong practical significance.

(1) In order to deal with the instantaneous current when motor starts, I put forward the way of PWM output to increase the service life of the chip module power;

(2) In order to deal with the sigal interference when the wiper returns, I put forward the way to use filter or a vote of the ways to reduce the noise signal interference with module;

(3) In order to deal with the recharge voltage of the wiper motor at low speed, I put forward the control module of wiper motor output what increase method of high power diode. 


\section{References}

[1] ZHU Hao, SUN Xudong. Starting Current Limitation Method of DTC Controlled Induction Machine for EV[C]//Proceedings of the Eighth International Conference on Electrical Machines and Systems(Volume I), Nanjing, 2005, 09:836-838.

[2] Lee Byoung-kuk, EhsaniMehrdad. Advanced Simulation Model for Brushless DC Motor Drives [ J]. Electric Power Components and System, 2003, 31(9): 841-868.

[3] Vipul Patel,Mark Steffka.Vehicular spark ignition systems radiated emissions and reception performance[J].IEEE Trans on Electromagnetic Compatibility,2005(5):19-23.

[4] Canavero F.Numerical simulation for early EMC design of cars[C].4 ${ }^{\text {th }}$ conference on electromagnetic compatibility,Brugge,Beligum,2000,9:32.39.

[5] Dale L.Sanders.'Using Image Planes on DC Motors to Filter High Freguencv Noise Dale.Sanders”,2004 IEEE EMC Symposium,Santa,Clara,CA.2004,aug:9-13. 